\title{
Integrating sustainable supply chain practices with operational performance: An exploratory study of Chinese SMEs
}

\author{
Niraj Kumar ${ }^{1 *}$, Andrew Brint ${ }^{2}$, Erjing Shi ${ }^{2}$, Arvind Upadhyay ${ }^{3}$ and Ximing Ruan ${ }^{4}$ \\ ${ }^{1}$ University of Liverpool Management School, Chatham Street, Liverpool L69 7ZH, United \\ Kingdom \\ (email:niraj.kumar.dr@gmail.com ) \\ *Corresponding Author \\ ${ }^{2}$ Sheffield University Management School, Conduit Road, Sheffield S10 1FL, United Kingdom \\ (email:a.brint@sheffield.ac.uk) \\ (email:erjingshi@163.com) \\ ${ }^{3}$ Brighton Business School, Moulsecoomb, Brighton BN2 4AT, United Kingdom \\ (email:A.Upadhyay@brighton.ac.uk) \\ ${ }^{4}$ Bristol Business School, University of the West of England, Coldharbour Ln, Bristol BS16 \\ 1QY, United Kingdom \\ (email:Ximing.Ruan@uwe.ac.uk)
}

Published in

"Production Planning \& Control: The Management of Operations"

$10^{\text {th }}$ May 2019 


\title{
Integrating sustainable supply chain practices with operational performance: An exploratory study of Chinese SMEs
}

\begin{abstract}
With growing regulatory and market pressure to implement green practices, SMEs are facing enormous challenges to simultaneously improve operational and green performances of their supply chains. The paper aims to understand the green practices adopted by Chinese SMEs in the packaging sector in order to assess the impact of these practices in improving the operational performance. Case study-based research methodology is adopted and semi-structured interviews are conducted to collect data from seven SMEs in this study. Both in-case and cross-case analyses are performed to understand the green practices being adopted with the focus on improving the operational performance. The findings of this study indicate that although most SMEs understand the importance of green practices, they have limited knowledge to integrate these practices to improve operational performance. Integration and alignment of green activities with the operational improvement measures are identified as critical factors to develop an efficient green supply chain.
\end{abstract}

Keywords: Green supply chain management, Operational performance, Small and Medium Enterprises (SMEs), Case study, Chinese packaging industry. 


\section{Introduction}

Chinese Small and Medium Enterprises (SMEs) are increasingly facing the challenges being imposed by higher environmental standards of the international markets and the ensuing need for a good environmental reputation (Zhu et al. 2008, and Lai and Wong 2012). Additionally, domestic environmental issues ranging from air emissions, resource shortage, and solid waste disposal are becoming increasingly important to both the Chinese government and the society at large. Chinese government is prioritising sustainable development in their policies and is tightening the environmental regulations in the manufacturing sector. Environmental certifications such as ISO14001, EMAS and MCERTS have been introduced and are being promoted to assess and monitor manufacturers' environmental performance. Facing this duel test from the market and the government, Chinese manufacturers have started looking for ways to enhance their production efficiency while minimizing the impact on the environment. Developing green supply chain practices has emerged as a win-win strategy for companies in terms of lowering environmental risk and increasing ecological efficiency at the same time (Van Hoek and Erasmus, 2000).

Green supply chain management (GrSCM) involves all participants and different stages in a product's life cycle covering purchasing, product design, manufacturing, distribution, marketing and after-life disposal. Although, GrSCM is not a new concept and widely discussed in past literature, its implementation in practice, particularly in Chinese SMEs context is still under trial. Some SMEs have realized its importance, but they lack the capabilities to put it into practice, while some misunderstand the concept which lead to unexpected results. SMEs are the key contributors in growing Chinese economy and have contributed to more than $60 \%$ of China's GDP and $68 \%$ of China's export in last few years. However, they have an extra disadvantage in terms of insufficient information, resources and expertise in implementing green principles (Lee, 2008). The performance of SMEs in implementing green practices can not only improve their environmental performance but can also influence their operational performance. There are a number of studies focussing on the large or state-owned manufacturing enterprises in Chinese context. However, limited studies are found discussing the implementation of green supply chain practices in SMEs.

Packaging as a high environmental sensitive industry has long been criticized for its low efficiency and high pollution (Verghese and Lewis, 2007). The Chinese packaging Industry is set to achieve significant growth between 2016 and 2021, at the annual growth rate of 5.4\%, compared to $4.5 \%$ during 2011-2016. This strong growth in China's packaging industry is mainly driven by the changing demographics and social factors, including rapid urbanization, 
rising middle class and an aging population (Xueyan, 2015). The Chinese government has realized the negative impact of excessive packaging and is encouraging companies to reduce the raw materials required in packaging to lower the environmental impact. However, the SMEs operating in the packaging sector have a long way to go to realize the comprehensive upgrading and transforming of industry, and so to change their public image (Zhang and Zhao, 2012). Therefore, the paper narrows its scope to the packaging sector considering its huge impact on environment to conduct an in-depth study. Lack of studies are found in literature discussing the implementation of green supply chain practices in packaging sector.

Despite the fact that sustainable supply chain has been recommended as a means of improving competitiveness, little empirical evidence exists in the literature validating its positive relationship with firm performance (Gopal and Thakkar, 2016). Particularly in case of Chinese packaging sector, limited research has been found to support the notion that sustainable practices promote better operational performance. In this regard this study focusses on understanding the green practices adopted by SMEs in Chinese packaging sector and explores the challenges and barriers faced to link it with operational performance improvement. The paper considers different processes involved during the life cycle of packaging from designing to disposal stage to understand the environmental issues and green practices being adopted, and investigate how these practices are linked to improving the operational performance.

In this paper, inductive research approach is adopted, allowing us to conduct in-depth investigation of green practices of sample companies. Data are collected from 7 SMEs in the packaging sector through semi-structured interviews. In-case and cross-case analysis approaches are adopted to explore the current practices and prospect of GrSCM implementation. Based on the empirical analysis of the data collected from case companies, this study evaluates the impact of green practices on operational performance and discusses the barriers and challenges of integrating green practices with SMEs operational performance. In addition, this paper proposes measures that can be used by SMEs to enhance their operational efficiency while implementing green practices.

The remaining part of this paper is organized as follows: Section 2 presents the review of literatures in GrSCM and Chinese packaging industry, critically analyses their relationship and provides solid theoretical foundation for this research. Section 3 discusses the exploratory conceptual framework and Section 4 presents detailed discussion over the research methodology adopted in this study. Section 5 analyses the empirical data and discusses the findings of both in-case and cross-case analyses. Section 6 discusses the implications of this 
study and provides the recommendations to practitioners. The last section concludes the paper with directions for future research.

\section{Literature Review}

\subsection{Green supply chain and performance}

In past, many researchers have focussed on different aspects of GrSCM to understand the impact on operational performance. Gilbert (2001) argued that GrSCM involves processes of incorporating environmental criteria in making organizational purchasing decisions and establishing long-term partnerships with upstream suppliers. Zsidisin and Siferd (2001) provided a more integrated view of green supply chain to improve performance by aligning different processes at the product life cycle including product design, acquisition, production, distribution, use, reuse and disposal of the enterprise's products and services. Davies and Hochman (2007) argued that for the comprehensive improvement of an organization's environmental performance, collaboration among all departments in an organization is required with common green objectives. Srivastava (2007) suggested end-of-life management of the product after its useful life to implement GrSCM practices. Moreover, the US Environmental Protection Agency (EPA 1998) identified four basic steps to effectively implementing GrSCM: identify costs, determine opportunities, calculate benefits, decide, implement and monitor. It draws an outline on how to concretely implement GrSCM and is of great importance in practice. In addition, Vachon and Klassen (2008) discussed the relationship between environmental practices and performance.

Some researchers explored the key criteria and capabilities for effectively implementing green supply chains practices. For instance, Darnall et al. (2008) compared capabilities for implementing green practices and an environmental management system. Handfield et al. (2001) discussed the dynamic cooperation among all departments within an organisation as a key competence to maintain healthy GrSCM practices which can improve performance. Yet, the extent of the above factors affecting an organization's practices of GrSCM differs from country to country, based on the economic status, industry and the organization's strategy. Therefore, some researches shift their emphasis to understand the impact on operational performance in a specific context to gain in-depth and targeted information.

Tseng et al. (2014) discussed a rigorous approach for benchmarking eco-efficiency in green supply chain under uncertainty and compared gain and loss functions as benchmarking tools in GrSC practices. Mohanty and Prakash (2014) presented an empirical study to conclude that 
Indian Micro, small and medium enterprises faced significant pressures from external stakeholders to adopt GrSCM practices. The study also found that external pressures and adoption of GrSCM are also fully mediated by internal pressures. Jabbour et al. (2017) analysed the relationship between critical success factors and the adoption of GrSCM practices for Brazil-based manufacturers of automotive batteries. They argued that firms using green training, green recruitment and selection, green performance evaluation and employee rewards will have more success in GrSCM implementation. Moreover, Yu et al. (2017) argued that both green purchasing personnel and green supplier selection have a significant positive effect on green supplier collaboration, and that building green collaboration with suppliers is significantly and positively related to both environmental and operational performance. Lee et al. (2015) discussed that firm's environmental performance can positively and significantly affect its competitive advantage. Furthermore, López-Torres et al. (2017) examined the effect of Knowledge Management (KM) as a platform to enable sustainability in firms' operations and to provide recommendations for managers to integrate sustainable operations into their business strategies. Garza-Reyes et al. (2016) and Cherrafi et al. (2017) discussed the implementation of green and lean approaches in the supply chain context to improve operational performance. Similarly, past literature such as Chaabane et al. (2011), Kumar et al. (2015) and Marshall et al. (2015) discussed multiple factors to consider while developing sustainable supply chains in practice.

Additionally, the link between GrSCM practices and enterprises' economic performance in the context of South East Asia is also discussed in past literature (Rao and Holt, 2005; Luthra et al. 2015). For instance, the impact of implementing green supply chain practices in Philippines is reviewed by Rao (2007); Hu and Hsu (2010) investigated the threats of green trade barriers and the application of GrSCM in Taiwan's electronics industry; Luthra et al. (2011) explored what hinders the implementation of GrSCM in the Indian automobile industry. They identified four top level barriers and one bottom level barrier that impede the practice. The top-level barriers are the cost implications, market competition and uncertainty, unawareness of customer and lack of implementing green practices while the bottom level barrier is lack of government support system. Lee (2008) also discussed the practice of GrSCM in South Korean industries, which heavily depend on the overseas market.

From the SME prospective, the active involvement of SME suppliers is necessary in developing green supply chain practices (Lee, 2008). SMEs themselves can be the key-player, but in most cases, they are playing a role of upstream or downstream supplier of large companies. Luken and Stares (2005) suggested that lack of information and technique makes it hard for SMEs to 
adapt to changes in environmental standards. As a result, SMEs may become the origin of environmental risks in effectively developing green supply chain. The development of SMEs has increasingly contributed to China's economic growth. They make up over 99 percent of all enterprises in China today. The output value of SMEs accounts for at least 60 percent of the country's gross domestic product, generating more than 82 percent of employment opportunities in China.

\subsection{Green practices in Chinese industry}

Sustainable development stresses the harmony between nature and human activities, which is in accord with the principle of GrSCM. Given its severe ecological and environmental issues, China has begun to implement sustainable development as a national strategy. GrSCM has a unique role in achieving sustainable development in China. Most of research on green supply chain has focussed on manufacturing sectors of Asian countries since the majority of the world's manufacturing products are from this area. Asian manufactures in particular are facing a number of challenges due to the increased monitoring and green regulations from Western markets and organisations, for instance, the European Union.

\subsubsection{Drivers}

Pressure from the global market is always regarded as an important driver for Chinese enterprises to implement GrSCM. The entry to WTO provides China with a great impetus for this development (Zhu et al., 2005). Following its economic opening, substantial foreign direct investments are pouring into the Chinese market. However, the abundant investment for the development of the manufacturing sector, exacerbates a series of environmental problems. A significant number of foreign companies have established offices and branches in China to purchase raw materials in order to save cost and to transfer their high polluting plants or programmes to China (Zhu and Geng, 2001). Simultaneously, Chinese manufacturers face the constant challenge of green barriers (Zhu et al., 2005). A large number of made-in-China products are returned because they fail to meet environmental requirements of Western market, which causes huge loss to companies. As a result, many manufacturing enterprises in China are getting into trouble. Especially for SMEs that have lower risk resistance capability, it is a serious problem. Having realized this challenge, Chinese manufacturing enterprises have begun to apply green practices in their value chain instead of a single plant (Zhu and Sarkis, 2004). However, many of them lack experience and capabilities. 
What's more, enterprises in high polluting sectors like chemical, petrochemical and transport, which closely relate to the supply chain of packaging enterprises, are more environmentally sensitive than those in other sectors (Deegan and Gordon, 1996). With the public's increasing awareness of the environment, enterprises in these sectors are being increasingly criticized for their pollution discharge (Zhu and Sarkis 2004). Besides pressures from the overseas market, reputation, law and environment are also considered to be crucial drivers for them to implement GrSCM. To maintain the volume and quantity of exporting products and to protect national environment, the Chinese government have set more strict laws to regulate the operation of enterprises. Specifically, environmental impact assessment like ISO14001 is promoted by the Chinese government - one of the aims being to meet the green requirements of foreign customers (Zhu et al., 2005). Moreover, the levers of price and tax are also used. The government has raised the tax on high-polluting enterprises and has put up the price of some critical resource to press related enterprises to make their value chain greener (Bai and Hidefumi, 2001).

\subsubsection{Barriers and Challenges}

Though these actions have achieved noticeable results and to some degree they have improved the status of GrSCM in China, there are still many problems existing in China. Zhu et al. (2005) argued that most Chinese enterprises excessively pursue export volume and over-focus on environmental impact certification, but they neglect the long-term environmental benefit. Even though some enterprises have realized the necessity of GrSCM, they are impeded by lack of knowledge and management skill and deficiency of financial strength especially in SMEs. Additionally, Zhu et al. (2005) also mentioned that some enterprises cannot apply green supply chain successfully because they don't have recycling systems. Thus, they are unavoidably weak in the product recovering phase and fail to make the whole supply chain green. Clark (2000) and Hall (2000) suggested that human resource is also one of the decisive factors that influence the implementation of GrSCM. Zhang et al. (1999) investigated this issue from the prospect of organizational culture. They believed that weaker corporate culture hinders the implementation of GrSCM in Chinese enterprises. Most of the research on GrSCM in Chinese context, have selected relatively large enterprises as samples. There is very limited research focussed on SMEs due to difficulties in data collection. However, as SMEs share a huge portion in the Chinese manufacturing sector, their contributions in reducing the carbon emission in this sector cannot be neglected any longer. 


\subsection{An overview of the packaging industry}

Companies and governments across the globe are increasingly looking to reduce the negative environmental impacts of the packaging systems. The packaging sector consumes a lot of natural resources and energy sources. They begin to see the limits of currently available raw materials for packaging and look for avenues for reusing and recycling packaging and search for greener raw materials for packaging. A new system for packaging is needed in which the consumption of raw materials could be reduced and materials could be reused and recycled. To implement an effective green strategy, it is vital to reduce the packaging waste, to save limited resources and to protect environment, and to apply the sustainability concept in material selection, processing, producing, storage, transport, reusing and recycle (Xueyan, 2015).

Early studies on packaging industry emphasised the communicative characteristics like colour and size. Function and appearance of the packaging were the most evaluated factors and the environmental issues have not drawn much attention (Roper and Parker, 2006). From the middle of 20th century, the packaging industry has been under pressure from media and consumers around the world because of its negative impact on the environment. Zhang and Zhao (2012) concluded that packaging can generate both solid wastes as well as liquid and gaseous pollution. Most of the criticisms particularly concentrate on the plastic packaging. Meikle (1995) stressed on the threats of plastic industry, saying that plastic packages have invaded every part of life and it will break the balance between human force and nature's power. Past literatures have focused on reducing the environmental impacts related to sourcing and producing packaging materials, and recovery of the materials at the end-of-life. Green strategies adopted in the industry include the selection of more renewable materials, using flexible materials in replace of rigid plastics, enhancing the efficiency and energy consumption involving sourcing, producing and converting packaging materials (European Council, 1994). Zailani et al. (2012) stressed on the importance of sustainable packaging by claiming that it has direct impact on a company's economic and social outcomes. Svanes et al. (2010) also described a holistic methodology for packaging design with Norwegian food industry as a case study. Huang (2017) argued that in order to increase the value of the goods, multi-layer packaging or expensive materials are used blindly resulting in the packaging costs even higher than the value of goods. Such packaging not only confuses consumers, but also wastes more resources, increase production costs and recovery difficulties, and are inconsistent with the development direction of green packaging. Therefore, packaging structure should be simplified on the premise of ensuring the performance. 
Williams and Wikstrom (2010) explored the environmental impact of food-packaging system with a life-cycle view. They identified six stages of food-packaging system: producing, waste handling, storage, marketing, distribution and consumer. However, little research on the waste content of packaging has been published. Although, packaging is identified as an important stage in the supply chain to protect the content from being wasted during transport, wholesale, retail and final consumption, the environmental impact of different types of packaging waste is increasingly being discussed in literature (Wikstrom et al. 2014; Accorsi et al. 2014). In fact, packaging process can play a crucial role in developing a sustainable supply chain. Green packaging is one of the importance and critical stages in improving not only the environmental performance of the company but also the economic performance.

In addition, the environmental impact of industrial packaging is also attracting increased attention in literature. Verghese and Lewis (2007) suggested the need for cooperation between supply chain approaches and environmental innovation in reducing commercial costs and optimizing efficiency in industrial packaging. Significant numbers of studies have discussed environmental issues in the plastics packaging industry. Pohlen and Farris (1992) examined the reverse logistics channels for recycling in plastics packaging. Brown (1993) also investigated the recovery phase of product life cycle in plastic packaging of food with the case of polypropylene-based snack food packaging.

Packaging characteristics can influence the distribution phase, as simpler and efficient packaging can reduce material used thus making the supply chain greener (Sarkis, 2003). Diabat and Govindan (2011) found that one of the most significant green practices in packaging industry is to reduce packaging materials and waste while satisfying the consumers' needs. Some literatures discuss the reasons why consumers fail to purchase environmental friendly packaging products. One direct and simple explanation is the lack of an alternative (BechLarsen, 1996). Lewis (2005) pointed that another reason is the lack of knowledge about the connection between their decisions and the consequences, as clear information is often not provided.

China's packaging industry has been growing at a rapid and stable pace over the recent years due to the growing economy and increasing middle class with higher purchasing power. China is already one of the world's largest packaging market, with fast-growing rates in segments such as paper packaging, flexible packaging, and rigid plastics packaging. While the global packaging market is constantly developing new packaging formats and materials, China is expected to remain as one of the leaders in the global packaging industry. Packaging companies 
in China are leading the way for a projected sales figure of $\$ 1$ trillion by 2020 (Xueyan, 2015). Nevertheless, most SMEs in this sector are facing challenges to adopting green practices in supply chain. Some scholars indicated that the pollution caused by packaging waste ranks the $4^{\text {th }}$ largest source of pollution (Zhang and Zhao, 2012). In 2012, the paper-making enterprises in China have suffered a setback, with a decrease of $70 \%$ in production compared to the previous year- Low manufacturing efficiency and concentration were directly responsible for this result, but other possible reasons may include failure to meet the environmental requirements.

The Chinese government has launched new regulations to better manage the environmental issues in the packaging sector. Specific measures include more strict material selection in plastic packaging, higher quality standards in liquid cartons and paper-based packaging, standardised labelling in food packaging, etc. The packaging industry has experienced high increasing regulatory and market pressure to adopt green practices not only in terms of the greener packaging material but looking beyond from the firm specific improvements to supply chain improvements.

\section{Exploratory conceptual framework}

This section presents an exploratory conceptual framework for understanding the green practices at different stages of the SC in packaging industry. The state of GrSCM in packaging industry involves many facets, and therefore, in addition to enterprises' concrete measures, subjective understanding and objective conditions in selecting the green practices need to be included in the analysis. According to Walker et al. (2008), GrSCM covers all stages of a product's life cycle, from the selection of raw materials, product design, manufacturing, distribution, use of the product by consumers to its disposal at the end of its useful life. For packaging enterprises, core stages include purchasing, manufacturing, logistics, and waste management. Previous researches have discussed these stages in the supply chain with the perspectives of the environmental objectives, such as, green purchasing (Zhu and Geng, 2001), green design (Tabone et al., 2010; Zhang et al., 1997), green manufacturing (Guide et al., 1996; Bras and McIntosh, 1999; Roy and Whelan, 1992), product recovery and waste disposal (Gungor and Gupta, 1999; Zhu and Sarkis, 2004) and reverse logistics (Carter and Ellram, 1998).

Many literatures in past have discussed the drivers and barriers of implementing GrSCM practices. For instance, Walker et al. (2008) presented the factors affecting the implementation of GrSCM into two groups: internal factors and external factors. Internal drivers include 
organization specific issues, and internal barriers contain lack of legitimacy and cost. External drivers include suppliers, competitors, customers as well as regulations, while external barriers cover poor supplier commitment, industry specific barriers and adverse regulations. Trowbridge (2001) also proposed that risk management is a significant internal driver of implementing green practices due to the potential possibility of interruption in the supply chain. Therefore, organizations have to collaborate with suppliers to find alternative materials and equipment, which can minimize environmental impact. However, for an investigation at macroscopic level, all the influential factors are interrelated. The internal and external factors are usually each other's prerequisites. Thus, it is difficult to limit them to a certain category. In addition, for packaging enterprises, the consumer is a crucial determinant that has a significant impact on their strategies. Sometimes consumers have conflicting expectations of sustainability and safety, and greater convenience at the same time (Lewis, 2005). It is rarely possible to achieve the perfect status of a strong function, safety, green and an excellent appearance simultaneously for a packaging enterprise.

The key questions we explore in this research are: What are the green practices adopted by SMEs in the Chinese packaging sector? and What are the drivers and barriers to integrate green practices with operational improvement? In this paper, the green practices adopted in the packaging SMEs are examined in terms of the green purchasing, green design, green manufacturing, green waste disposal and green logistics processes. The influential factors in terms of drivers and barriers of effective implementation of green practices to improve operational performance are also explored in this paper. Figure 1 presents the exploratory conceptual model which highlights different processes considered in this study.

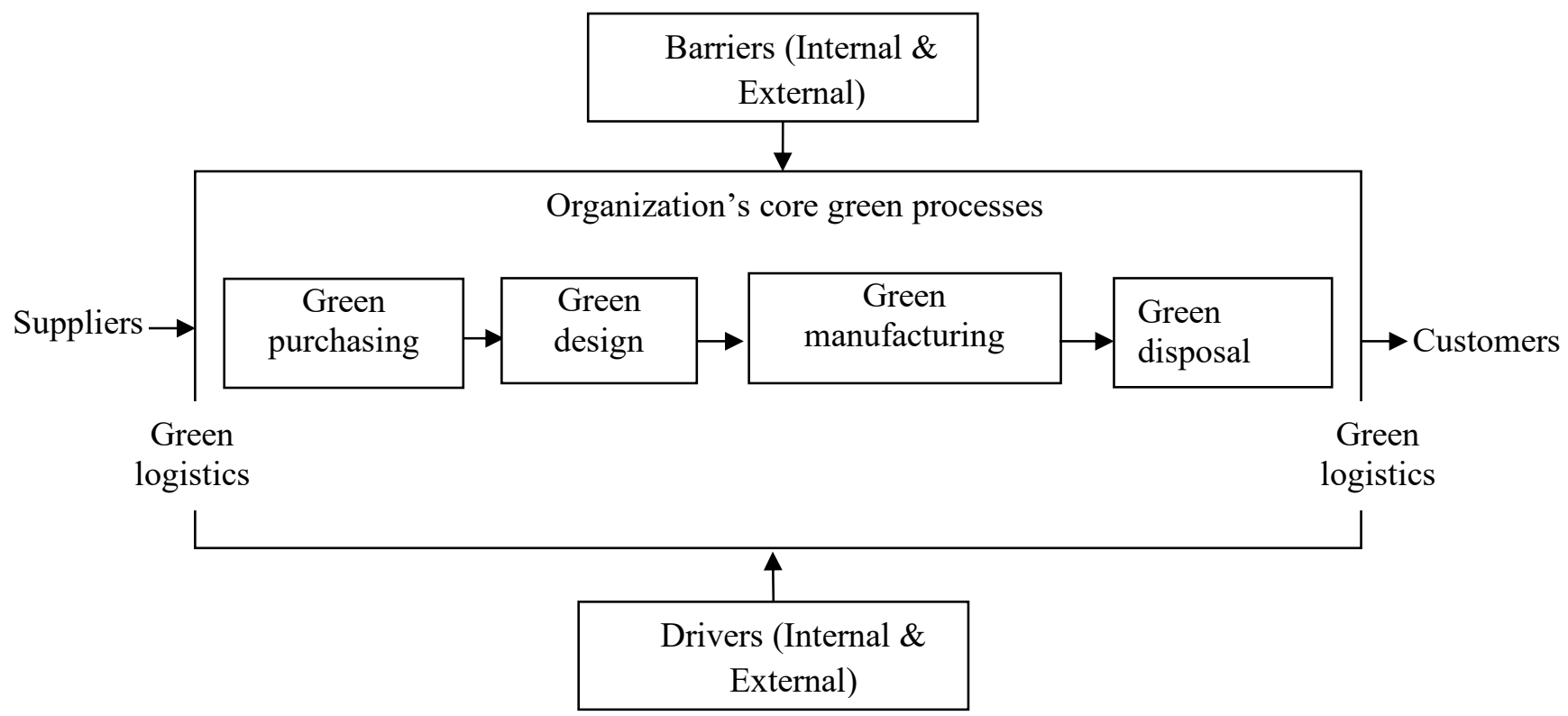


Figure 1: Exploratory conceptual framework

\section{Research Methodology}

This research adopts the case study based research methodology (Patton 2002, Yin 2017) to understand the green practices currently being adopted at different stages of the supply chain and to explore the challenges in integrating these practices to improve operational performance. In this study, we have conducted 21 semi-structured interviews with senior managers of 7 case companies. The selection of 7 case companies are made on the basis of the most commonly used packaging materials such as paper / cardboard-based packaging, plastic based packaging, Glass based packaging and metal based packaging materials. The sampled companies have sales revenue lower than 100 million RMB and the number of employees between $100-500$, which keeps than in the category of SMEs, as defined by Chen (2006). The sample companies also do not have any foreign or state investment.

Different packaging materials have unique characteristics. For example, paper and cardboard based packaging can be cheaper to produce with some added benefits of easy to recycle. However, it also has limitations of not water-resistant and could be easily damaged. Plastic based packaging has become very popular in modern days due to versatile uses of flexible and rigid plastics which could be moulded into different shapes. It has light weight and cheaper to produce in bulk. However, one of the major problems with most of plastic based packaging is it is difficult to dispose of in environment friendly ways and creates huge problems for environment. Metal based packaging can be more durable, impermeable and can sustain heat processing. Metal based packaging could be partially or fully recycled based on the characteristics of the particular metal and alloy. However, the metal-based packaging can contaminate the materials enclosed as it may react with the material contained in the package. Glass based packaging could be easy to reuse and recycle, but has a limited application particularly for liquid materials. However, Glass based packaging could be heavy, fragile and may have safety issues.

The semi-structured interviews conducted for data collection in this study is suitable for the exploratory nature of the study (Yin 2011). In semi-structured interviews, questions are designed within a specific topic but not standardised (King, 2004). Hence interviewees are given freedom to express their own experience and attitudes. The order of questions as well as the length of the interview can be changed and the way of asking questions is alternative 
depending on the interviewee's responses and the context of sample enterprises (Flick, 2014). In this regard, semi-structured interview is the most appropriate approach to collect qualitative data in this research. The interviews are conducted to understand the impact of green practices on operational performance of the company. The interview questions were focussed on different processes in the supply chain ranging from procurement of raw materials, packaging design, manufacturing, logistics processes to waste disposal. In each company, three senior executives were interviewed for about an hour, and therefore, total 21 interviews were conducted to collect data. The profile of the case companies and interview participants are summarised in Table 1.

Table 1: Profile of case companies and participants

\begin{tabular}{|c|c|c|}
\hline Company & Main business & Job title of interviewees \\
\hline \multirow[t]{3}{*}{$\mathrm{A}$} & \multirow[t]{3}{*}{ Paper based packaging } & General manager \\
\hline & & Production manager \\
\hline & & Deputy general manager \\
\hline \multirow[t]{3}{*}{$\mathrm{B}$} & \multirow{3}{*}{$\begin{array}{l}\text { Glass and Paper based } \\
\text { packaging }\end{array}$} & Design manager \\
\hline & & General manager \\
\hline & & Sales manager \\
\hline \multirow[t]{3}{*}{$\mathrm{C}$} & \multirow{3}{*}{$\begin{array}{l}\text { Metal based packaging } \\
\text { such as Tins }\end{array}$} & Director of operation \\
\hline & & Head of operation \\
\hline & & Material manager \\
\hline \multirow[t]{3}{*}{$\mathrm{D}$} & \multirow[t]{3}{*}{ Metal based packaging } & General manager \\
\hline & & Sales manager \\
\hline & & Technical manager \\
\hline \multirow[t]{3}{*}{$\mathrm{E}$} & \multirow{3}{*}{$\begin{array}{l}\text { Plastic based } \\
\text { packaging }\end{array}$} & General manager \\
\hline & & Production manager \\
\hline & & Vice manager \\
\hline \multirow[t]{3}{*}{$\mathrm{F}$} & \multirow{3}{*}{$\begin{array}{l}\text { Plastic based } \\
\text { packaging }\end{array}$} & Vice manager \\
\hline & & Finance director \\
\hline & & Head of operation \\
\hline \multirow[t]{3}{*}{ G } & \multirow{3}{*}{$\begin{array}{c}\text { Metal based packaging } \\
\text { such as Tins }\end{array}$} & General manager \\
\hline & & Director of operation \\
\hline & & Vice president \\
\hline
\end{tabular}

Though some researchers argue that the term validity is not applicable to qualitative research, qualitative researches need a criterion to check their qualities (Golafshani, 2003). McMillan and Schumacher (2006) discussed validity as the extent of consistency between the explanations of the phenomenon and the reality. This also ensures that the findings of the study reflect the real situation. After the interviews, we emailed the transcript and our notes on it to the interviewee to ensure that we have understood the interviewees' opinion correctly. It also 
ensured the validity and reliability of collected data and provided confidence that no important information was missed. All responses collected during interviews are transcribed and coded for analysis purpose. To further ensure the validity and reliability of data, non-verbal behaviours of participants was also taken into consideration in the transcribing process (Kvale and Brinkmann 2009). Flynn et al. (1990) suggested that transcription is useful to improve the interviewing techniques, to detect the presence of leading questions on the part of the interviewer and to guard against selective memory. Further, codification of transcripts helped to develop the pattern of the information emerged.

Along with primary data from interviews, secondary data from annual reports and relevant documents were also analysed to strengthen the findings of this study. The reliability of the collected data was ensured by interviewing three different executives from each case company. The responses of these executives helped to cross-check the information provided to ensure that quality data were collected.

\section{Analysis and findings}

In this section, the responses of senior executives of each case company is analysed to understand the key sustainable practices adopted by these case companies. The qualitative data collected is analysed in 3 phases, Description, Analysis and Interpretation (Wolcott 1994). The content analysis of the qualitative data is performed to understand the key theme emerging from the interviews. Later on, the practices across these cases are compared to analyse the common practices in the sector. Further, the motivations and challenges to implement these green practices across the product life cycle are analysed to explore common themes and issues to provide a more generalised view of the barriers faced by Chinese SMEs in packaging sector in order to implement sustainable practices to improve their operational performance. The analysis of interviews was focussed on 5 key processes: Purchasing, product design, production, logistics and waste disposal.

\subsection{Green practices adopted by SMEs}

Each case is individually analysed to understand the implementation of green practices at different stages of product life cycle and to explore the impact of these practices on improving the operational performance.

\subsubsection{Green purchasing}

Green purchasing refers to environmentally conscious purchasing activity in the organisation that promotes recycling, reuse, and waste reduction from the source (Carter and Ellram 1998; 
Min and Galle, 2001). Knowledge and skill development of the purchasing function can be recognised as an important resource in building green supply chain capabilities and performance (Yu et al. 2017).

To understand the green practices adopted in the purchasing activities, SMEs were asked questions related to whether they consider: the sustainability criteria in procuring raw materials for packaging; the environmental concerns of the materials used for packaging; Sustainability as a key criterion for supplier selection along with cost and quality. Both aspects of internal and external factors responsible for ensuring green purchasing were considered in this study. The procurement practices of all the case SMEs were compared to analyse what were the popular practices and what were the barriers and challenges in effectively implementing these green practices.

In the packaging sector, SMEs mainly manifests in the selection of right material for cost effective packaging. However, they look for raw materials that compliant with relevant environmental standard. Some case companies pay more attention to green purchasing practices due to market competition and customer requirements while others try to increase their social reputation and improve their overseas customer base through satisfying their green material criteria for packaging. However, in most cases, environmental consideration was limited to avoid any regulatory risks and was given less importance as compared to cost and quality criteria of raw materials. Table 2 presents the case companies' green purchasing practices. Some of the specific green practices adopted by case companies are highlighted in the following quotes from the executives of the case companies.

An executive highlighted, "As a certified green printing company, there is a strict limit on the content of heavy metals and VOC (Volatile organic compound) in raw materials. We are required to use only materials that meet the relevant environmental standard. Specific green practices include using FSC certified paper and certified green printing ink, using green consumables that can produce a better printing effect with lower price, for example, the alcohol-free solution can enhance efficiency and save cost simultaneously." Most executives mentioned that "Quality and price play more important role than environmental factors in decision making process. We only look into whether the materials are compliant with national environmental standard."

Only a few of executives agreed to work with suppliers to improve environmental performance and highlighted that "The company takes environmental concerns seriously. Our current 
Production Planning \& Control: The Management of Operations 2019;30(5-6):464-478.

practices include cooperating with suppliers who provide high quality materials that are up to national environmental standard and establishing review system to evaluate suppliers' product quality and production process."

Table 2: Summary of Green purchasing practices

\begin{tabular}{cl}
\hline Company & Green Practices \\
\hline A & $\begin{array}{l}\text { Used FSC (Forest Stewardship Council) certified paper and certified } \\
\text { green printing ink, use green consumables that can produce a better } \\
\text { printing effect with lower price }\end{array}$ \\
B & $\begin{array}{l}\text { Environmental factors are considered but not extensively; Raw materials } \\
\text { procured only need to be compliant with national environmental } \\
\text { standard. } \\
\text { Collaborated with suppliers to ensure high quality raw materials } \\
\text { compliant with the national environmental standard; Established } \\
\text { effective monitoring system to evaluate the environmental impact of the } \\
\text { raw materials and suppliers' environmental performance. } \\
\text { The production of bottle cap and printing ink requires environment } \\
\text { certification and materials need to compliant with relevant national } \\
\text { standards; however more attention has been paid to the quality of raw } \\
\text { materials rather than the environmental criteria. }\end{array}$ \\
More attention to cost comparted to the environmental factors; Select \\
reliable suppliers who have a reputation to use less harmful raw \\
materials. \\
Less attention to environmental impact than to cost and quality. \\
Purchased recycled aluminium scrap; cooperate with suppliers who \\
provide high quality materials satisfying relevant environmental \\
standard.
\end{tabular}

\subsubsection{Green design:}

The main purpose of green design is to develop environmental friendly products and process having less impact on environment (Russo and Rizzi, 2014). The executives were asked to express their views on whether they consider the environmental impact of packaging while designing the packages for different products, whether they have the capability to improve the packages design to make it environmental friendly, whether they consider innovative approaches to reduce the carbon foot print of the packages, whether they design packaging for reuse, recycle, and recovery of materials at the end of lifecycle etc. They were later asked questions related to drivers and barriers for adopting green design principles such as design for environment or considering the environmental impact through the life cycle of the packaging. It is observed that production cost, production waste and functionality were most important factors considered in packaging design stage. Most interviewees mentioned cost as first priority 
in deciding their packaging design, which was followed by the design creating low waste, and multi functionality of packaging. Mostly at the packaging design stage, the selection of raw material, potential production cost, and the amount of wastage of material were considered. Although, some of these practices also supports the environmental objectives in terms of reducing the raw materials usage and wastage in the production process, It is apparent that specific efforts to implement "design for environment" principles were not evident in case companies. In most of SMEs, selection of environmental friendly raw materials was only adopted when it was required by the law or it helped to reduce the packaging cost. SMEs were not proactive in building the green thinking at the designing stage.

\subsubsection{Green manufacturing:}

Green manufacturing supports the reduction of environmental impact of manufacturing processes. Executives were asked to express their views on whether they have reduced reliance on non-renewable sources for energy and raw materials to manufacture packaging, whether they have adopted green production processes, whether they have adopted practices to reuse and recycle used materials to manufacture new packaging, whether they have consistently reduced the usage of hazardous materials during production etc. Most of the executives at case SMEs highlighted a number of green practices adopted at the manufacturing stage. For example, an executive at one of the SMEs mentioned that "In manufacturing phase, we aim to reduce the amount of hazardous raw materials and increase the use ratio of consumables. We also work on reducing the number of industrial processes that may lead to serious pollution."

Similarly, a senior manager at another company discussed that "In manufacturing process, the company reduces waste by ensuring maximized use ratio through strict material selection." Some of the managers also highlighted that "We use innovative manufacturing processes to reduce the amount of metal used in production by making thin metal cans. " Moreover, a general manager of one of the SMEs mentioned, "In the manufacturing process, the company reduces iron dust and scrap material by accurate measurement and using just the right amount of raw material. It also uniformly reclaims iron sheets and wooden cases, utilizes leftover materials from big spare parts to produce small ones." Furthermore, the production manager at one of the case companies discussed that, "In manufacturing stage, the company improves the production process and uses new technologies to raise the use ratio of raw materials thus to minimize waste."

Table 3 shows SMEs' key green practices in improving the manufacturing process. Increasing use ratio of material and reducing waste rate were two main measures of green manufacturing 
processes. Specific practices also included improving production process and enhancing technical level to integrate sustainable practices with operational improvement.

Table 3: Summary of green manufacturing practices

\begin{tabular}{cl}
\hline Company & Green Practices \\
\hline A & $\begin{array}{l}\text { Increased use ratio of consumables; Reduced waste by adopting } \\
\text { advanced technologies; Used environmental friendly consumables; } \\
\text { Used as few industrial processes as possible that may lead to serious } \\
\text { pollution. } \\
\text { Maximized use ratio through optimised material selection; Enhanced } \\
\text { technical level; Linked the performance of employees in production } \\
\text { stage with the amount of waste created as a negative indicator. }\end{array}$ \\
& $\begin{array}{l}\text { Improved technical innovation and reduced the amount of metal used } \\
\text { as raw material; }\end{array}$ \\
R & $\begin{array}{l}\text { Reduced iron dust and scrap material by accurate measurement; } \\
\text { Used just the right amount of raw material; Consistently reclaimed } \\
\text { iron sheets and wooden cases after use; Utilized leftover materials } \\
\text { from big spare parts to produce small ones; Used suitable technology } \\
\text { and processes to reduce the environmental impact. }\end{array}$ \\
& $\begin{array}{l}\text { Improved the production process and adopted advanced } \\
\text { technologies to reduce pollution. } \\
\text { Recycled waste; Maximized use ratio; Reduced rejection rate. }\end{array}$ \\
& Esed advanced production line; Reduced rejection rate. \\
\hline F &
\end{tabular}

\subsubsection{Waste disposal:}

Waste disposal practices in this study are linked to how SMEs manage manufacturing waste. To understand the green practices in the waste disposal, the executives were asked for their views on how they handle wastes and what measures they have taken to reduce, recycle and recover wastes. They were also asked whether they dispose waste in environmentally friendly ways and try to consistently reduce the amount of waste to landfill.

Most of case companies send waste to qualified waste disposal or recycle companies. Some of the SMEs like Company F as a participant of "Recycle of Waste Package Materials" program has had successful practices in waste recycling with the support of National Ministry of Science and Technology. Company D has recycling equipment to process waste gas and water. The executive at company A highlighted that "reusable wastes are treated by recycling companies while those dangerous and cannot be reused are transferred to qualified companies. " Company $\mathrm{B}$ encourages their employees to reduce rejection rate. The senior managers at the company 
discussed that "methods used to manage waste include sorting wastes and sending them to refuse disposal companies, and processing waste water and gas to make them less harmful for environment." Similarly, executives at Company C and G highlighted that, "In terms of waste management, the company presses defective products into metal blocks and sell them to waste recycling companies rather than sending it to landfill." Table 4 presents the green practices adopted by case companies for waste disposal.

Table 4: Summary of waste disposal green practices

\begin{tabular}{cl}
\hline Company & Green Practices \\
\hline A & $\begin{array}{l}\text { Uses recycling companies and other qualified companies for waste } \\
\text { disposal. }\end{array}$ \\
B & $\begin{array}{l}\text { Sorts and sends to refuse disposal companies; Processes waste water. } \\
\text { C }\end{array}$ \\
$\begin{array}{l}\text { Presses defective products into metal blocks and sells them to waste } \\
\text { recycling companies. }\end{array}$ \\
$\begin{array}{l}\text { Sends the iron dust generated in the production process to steel } \\
\text { plants; Active carbon and other recycling equipment are used to } \\
\text { absorb waste gas. }\end{array}$ \\
Reclaims part of the wastes and sell the rest to companies \\
specializing in recycling of waste plastics. \\
F & $\begin{array}{l}\text { Sorts the waste and sends to refuse disposal companies; } \\
\text { Presses defective products into metal blocks and sells them to waste } \\
\text { recycling companies. }\end{array}$ \\
\hline
\end{tabular}

\subsubsection{Green logistics:}

Discussions of green logistics in this paper focus on transportation and distribution of packaging raw materials and finished products. Executives at case companies were asked for their views on how environmental factors influence the transportation and distribution activities, and how companies are making their logistics operations greener. They were further asked, whether they take the help of the third-party logistics to improve their green performance; whether they use fuel-efficient vehicles in the logistics operations; whether they optimize the transportation routes for logistics operations; whether they use energy-efficient warehouses etc.

During interviews, executives at all case companies highlighted carbon emission as one of the key concerns in logistics operations. For this reason, most case companies entrust products transportation to expert logistics companies. In terms of distribution, some of companies set up facilities near to customers to reduce transportation distance, and therefore reduce the carbon emission. Executives at Company A mentioned that, "We use specialised logistics companies 
which optimises the route and resources to reduce the unnecessary carbon emissions during transportation." Similarly, Senior managers at Company B highlighted that, "We rely on expert third party logistics to reduce carbon emission during transportation." However, mangers at company $\mathrm{C}$ discussed that " the company set up its branches in the places where main consumers concentrate. This helped to increase the use ratio of vehicles and to reduce carbon emissions."

\subsubsection{Environmental certifications:}

Environmental certifications can be a strong stimulus to companies to implement green practices. Major certifications adopted by Chinese SMEs mostly include ISO14001 and EMAS. ISO14001 is the main environmental certification at present aiming at manufacturing enterprises. A series of guidelines and processes are developed to help enterprises to reduce manufacturing costs while minimizing environmental impact (Chen, 2005). Other certifications are less popular because they are specific to particular industries or manufacturing processes (e.g. Green printing certification, Carbon Trust Standard etc.). Some of the SMEs (A, C, F, G) hold environmental certifications (ISO14001) which highlights the green practices adopted in their facilities and processes.

Companies who are holding one or more of environmental certification tend to proactively adopt more sustainable practices. They work on limiting their use of heavy metals and volatile organic compounds in their raw materials and processes. These companies use only materials that meet the relevant environmental standard. They tend to link these practices to improve the efficiency of their processes and save cost. For example: Company A uses FSC certified paper and certified green printing ink, using green consumables that can produce a better printing effect with lower price, for example, the alcohol-free solution can enhance efficiency and save cost simultaneously.

\subsubsection{Comparing the green practices of case companies}

Most of the case companies have implemented some level of green practices in their operations. However, some of the SMEs were involved in these practices to mitigate the regulatory risks in domestic and global markets. Only a few of the SMEs proactively adopted green practices beyond the standard legal requirements and tried to link it with the operational improvement measures. These SMEs performed better on environmental parameters. Moreover, SMEs with environmental certifications performed better than their counterparts in implementing green 
practices. However, it's worth mentioning that company D has implemented many green practices in their operations but it does not have environmental certifications. The executives of company D highlighted that they mostly focussed on improving the green performance of their company and have not extended it to the supply chain. They have poor monitoring of suppliers' practices and therefore it is difficult to know whether suppliers are adopting environmentally friendly processes and raw materials. It is observed that green practices in the purchasing function of the company is limited and four SMEs have showed lack of interests to improve their green performance in purchasing, mostly due to the increase in the cost of raw materials. Executives at these SMEs Highlighted that "fierce competition and poor profits are major obstacles to implementing green purchasing practices."

\subsection{Motivations of adopting green practices}

Based on the interviews of executives, the key drivers of adopting green practices are identified as environmental regulations, tax subsidy, customers' requirements and competitors' green performance. All the executives of case companies agreed that environmental regulations have forced them to think about implementing green practices in their operations. Adopting green practices helped them to mitigate the regulatory risks and to avoid getting fined. They further agreed that government plays a very important role in deciding the environmental standards of the packaging sector. Getting the tax subsidies and financial benefits from the government were identified as second most popular motivating factor for SMEs. Executives of company D expressed that "if the government put relevant laws and regulations and set up industry standards, the SMEs would implement green supply chain practices."

Customers' requirements for green products and competitors' better performance on environmental indicators were equally considered influential in adopting green practices. The executives of company A highlighted that "our customers want the packages to be reusable, recyclable and harmless to human being, and therefore we need to keep innovating to comply with the customers' requirements". Moreover, Senior managers at company B stated that "Potential drivers that may stimulate SMEs to implement GrSCM practices include preferential policies like tax reduction and exemption as well as customer's requirement”. However, executives of company $\mathrm{C}$ mentioned that "Competition from other companies in the sector is also a crucial driver."

None of the executives explicitly mentioned that they adopted green practices to improve their profits. It seems that SMEs were mostly influenced by external factors in order to implement 
green practices in different operations. They may not have realised the importance of these practices in not only improving their environmental performance, but also the operational performance. They lack the knowledge and skills to effectively implement green practices at the supply chain level. Jabbour et al. (2017) analysed the relationship between critical success factors and the adoption of GrSCM practices for some Brazilian manufacturers of automotive batteries, and argued that firms using green training, green recruitment and selection, green performance evaluation and employee rewards will have more success in GrSCM implementation. SMEs holding environmental certifications are more likely to be optimistic to and have better knowledge of the environmental friendly practices. Regional advantages like preferential policy and convenient information access in different areas of China boosted SMEs' confidence in adopting green practices. In addition, economic scale advantage is equally important to packaging enterprises to realize upgrading and transforming under the pressure of customers' green requirement.

\subsection{Barriers and challenges of adopting green practices}

All 7 case companies regarded cost as their main barrier of implementing GrSCM practices. Environmental friendly raw materials are expensive and therefore, many small companies cannot afford it. Even companies that have implemented green practices feel overt pressure due to increase in the cost of raw materials. Not having appropriate policy and regulations is another barrier for SMEs. Most interviewees deemed that lack of relevant policies and regulations should be held responsible for disorderly competition and ineffective implementation of green practices in the industry. Lack of technical know-how, less integrated supply chain and unskilled human resources were equally responsible for creating further challenges for SMEs to improve environmental performance. Most executives expressed that it is unrealistic for them to hire professionals to implement GrSCM practices, due to the shear small size and limited resources. Not having adequate recycling infrastructure and underdeveloped reverse logistics channels further limits the implementation of green practices at the supply chain level. Improper alignment of green objectives among different players in the supply chain creates further challenges in order to search for optimal solutions for the environmental problems. Dia and Govindan (2011) discussed that one of the most significant practices of green supply chain management in packaging industry is to reduce packaging waste. However, executives of Company $\mathrm{C}$ shared that, " the lack of collaboration and coordination among supply chain partners negatively impacts the recycling of packaging wastes". 
Executives of company A agreed that "One of the key barriers of GrSCM is to manage the cost of green products in line with what customers can afford." They also highlighted that Government policies are not supportive to motivate the green producers. Further, the general manager of the company A expressed that “ adopting green supply chain practices is good for the future of the company, but it will take some time before it can be widely implemented across Chinese SMEs". The practitioners at Company B discussed that the technical constraints and, high cost of raw materials and skilled human resources were some of the key barriers for adopting green practices. They further added that complex processes and lack of knowledge impede the development of GrSCM. Company $\mathrm{C}$ faced difficulties such as blockade on new techniques, sluggish recycling channels, financial pressures and lack of favourable policies and regulations in order to effectively implement environmental friendly practices. For Company $\mathrm{D}$, high implementation cost and insufficient resources were the two main barriers of developing green supply chain. Executives of companies E paid more attention to cost than environmental factors in their decision making and highlighted that the high cost of green materials and low level of technical know-how were the key barriers in the packaging industry.

\section{Discussion}

In the global business environment, Chinese packaging sector is facing dual challenges of improving their environmental performance while boosting their profits. Nevertheless, SMEs in this sector are in an even more difficult situation. They are struggling to survive in the fierce competition with large enterprises, while also being criticized by both domestic and overseas customers for poor environmental performance. Based on the empirical findings of this study, a picture of current situation of sustainable practices and its impact on operational performance can be drawn.

This study has observed that SMEs in Chinese packaging industry show awareness over the importance of sustainable practices for businesses and society. They were aware of the impact of green practices on firm performance. However, cost is one of the key factors which plays crucial role in wider implementation of the green practices. Lack of knowledge over the right approach to implement green practices is one of the inhibitors to successfully implement these practices. Yu et al. (2017) also recognised the knowledge and green skills development as important for building green supply chain capabilities and improving performance. Lack of customers' enthusiasm for green products and lack of supportive environmental policies were some of other critical issues identified. Access to innovation and technology to improve the 
environmental performance of product and processes also create further challenges for green implementation.

Most of the case SMEs has explored some environmental certifications for the company to benchmark their processes on the industry standards. Companies with environmental certifications perform better than their counterparts in greening their operations. Although, all of the case SMEs have achieved the minimum level of environmental standards required by the law, only a minority of them tend to look beyond the minimum compliance and actively evaluate their processes to reduce the negative impacts on environment. Most of the SMEs were more concerned about the implementation of practices inside their firm boundaries and do not think about extending it to the supply chain level. Although, some evidence of green practices in manufacturing, and waste disposal were found, limited evidence in context of product design and green purchasing were found. It is also observed that most of the executives do not leverage on their sustainable practices to drive the operational improvement. Different underlying causes for not integrating sustainable practices with the operational performance could be classified under following themes:

\subsection{Lack of proactive strategy for implementing green practices:}

SMEs are overly depended on external regulations and environmental certification agencies to guide their green implementation plan. Most SMEs appear to follow the traditional "commandand-control" model suggested by Hsu et al. (2013) and only engages in green initiatives to meet relevant regulations and environmental certification requirements. Some of the activities where environmental certification is not demanded, most of companies may not bother to implement green practices. Lack of initiatives to develop innovative green processes is another challenge. Additionally, short-term benefits of implementing GrSCM practices are not obvious, and SMEs may not be willing to wait for long to realise the return on investment on green practices. At the same time, blockade on advanced green technology from some developed countries creates further challenges for green implementation. SMEs are not proactive in improving their current processes to deal with emerging environmental challenges unless they see the financial risks to their business in near future.

\subsection{Lack of voice in the supply chain:}

In fact, the lack of voice in the supply chain is to a large extent responsible for the poor performance of SMEs in developing green supply chain in packaging sector. Pressures from 
large enterprises are much more effective for promoting green practices in the supply chain (Ytterhus et al., 1999). Not aligning the environmental objectives at the supply chain level further creates challenges for effectively implementing the green practices.

\subsection{Implementation of GrSCM still at the early stage:}

Most SMEs are lacking the experience and skills to implement green practices (Zhu and Sarkis, 2006). Besides, unclear and ambiguous green standards across the life cycle of packaging are problematic for achieving green objectives. Relevant environmental regulations and standards usually focus on one or two activities and processes in the supply chain such as manufacturing or waste management. Due to the lack of scientific guidance and knowledge of the green processes, the development of GrSCM in Chinese packaging sector is full of uncertainty. SMEs should improve the recycling and reuse channels and try to "close the loop" in their manufacturing operation. With limited resources, reusing and recycling are becoming increasingly important to reduce the burden in environment. Developing a corporate culture of environmental management is crucial. Many SMEs have recognized the benefit of green supply chain, but lack in motivations to implement it. The most fundamental solution is to make it the responsibility of everyone. Not only managers, but also employees should have such awareness.

\subsection{Lack of information sharing with suppliers:}

Sharing and integrating information at the supply chain level is crucial to improve the green performance (Lin and Ho, 2008). However, information linkages between packaging SMEs, and their suppliers and customers are loose. Unlike large enterprises that have abundant information resources and extent contacts with suppliers as well as customers, SMEs have lack of channels to access suppliers and customers' information. As a result, SMEs feel that there are many factors "beyond their control" when they think of implementing the green practices at the supply chain level.

\subsection{Lack of customers awareness of green packaging:}

Customers' awareness of green packaging and its impact on environment is very limited in China. Customer awareness can be a strong driver for SMEs to implement green practices. If customers demand green products, companies would improve their manufacturing processes and develop a greener supply chain (Luthra et al., 2011, Zhu et al. 2012). Nowadays, though green packaging has become increasingly popular, traditional practices of buying nicely wrapped products remains the main choice of many customers. Promotion of green 
consumption among general public to increase the demand for green products is extremely important.

\subsection{Inadequate support for green transformation:}

As a main exporter of packaging products, China has paid huge price on just seeking economic profits at all cost. There is a need to look beyond the economic performance and incorporate environmental and social indicators in measuring the performance of SMEs. Enhanced government involvement in promoting green practices in SMEs is desired to improve sustainability performance of the packaging sector. The Government has a responsibility to set up clear standards and regulations, perfect supervising mechanism and provide expert guidance to SMEs to adopt green practices. Incentive and supportive financial policies can effectively help to cut down barriers for implementation. For example, tax incentives and affordable loans can alleviate SMEs' financial stress in upgrading their resources. In addition, if a specialized information network of companies in packaging and allied sectors is established to provide detailed information about the environmental standards and best practices, it will be more convenient for SMEs to learn and compare their current practices and improve their performance.

\section{Conclusion and future research}

The implementation of GrSCM practices in Chinese packaging sector is at an early stage. It heavily rests on isolated green practices of different entities in the supply chain rather than a coordinated effort among all the players to achieve the green objectives (Lee, 2008). Lack of relevant standards and policies, and sluggish information sharing in the sector have impeded the growth of GrSCM. Therefore, to improve the situation, the Government could play a leading role through reforms in various aspects to create a right condition for spreading the environmental friendly practices in the supply chain. Simultaneously, SMEs needs to develop a systematic approach to integrate the green objectives with the operational improvement measures to realise the short and long-term benefits. Fortunately, majority of SMEs are optimistic about the future of GrSCM in Chinese industry.

This study makes theoretical contributions in understanding the state of green practices adopted by Chinese SMEs across the product life cycle of the packaging. The motivations and barriers to implement green practices discussed in this paper could help to understand the challenges in developing green supply chain in China. Limited studies in past have focussed on SMEs in packaging sector and therefore, this study makes significant contributions in providing insights 
into how to improve the environmental performance of SMEs. Analysing and comparing the green practices of the case companies provides useful information about the internal and external factors responsible to promote green practices in the Chinese packaging industry. The pragmatic insights provided in this study have the potential to further enhance the understanding of implementing green practices not only inside the boundary of the firms, but extend it to their supply chains. Different processes across the packaging life- cycle from packaging design to waste disposal stages considered in this study intend to investigate whether the green practices are adopted at the early stage of product life cycle. Implementing green practices at the packaging design stage would be more effective to improve the green performance across the product life cycle. However, in this study limited evidence has been found to support that the SMEs are implementing 'green thinking' at the early stage of the packaging life cycle.

Moreover, there is limited discussion in literature to understand the impact of green practices on operational performance, particularly in context of SMEs in developing countries. Therefore, this paper contributes in developing this crucial understanding by conducting in-depth exploratory study in multiple case scenarios. This study is one of the few that have considered the environmental sustainability practices in the packaging industry in Chinese context. The findings of this study may help the practitioners in making strategic and tactical decisions regarding successful implementation of green supply chain practices in Chinese packaging industry which could significantly affect their sustainability performance. The study could further help the practitioners to deal with the potential challenges discussed in implementing green practices in the supply chain. We believe that the findings of this research will encourage SMEs to become proactive in integrating the green objectives with the operational performance to remain competitive in the global market.

Although this study provides some valuable insights over the implementation of sustainable practices in the Chinese packaging sector, a number of opportunities for future research could be originated based on the discussion presented in this paper. The study only considered seven case companies, and one can argue that this may not be sufficient to generalise the findings. However, this limitation of case study research methodology is well documented in literature. Nevertheless, bigger sample size and alternative methodologies such as survey research and mixed methods could be used in future studies to further provide more in-depth understanding of the environmental performance of SMEs in China. Moreover, the SMEs selected for this study are registered in China Packaging Federation, which means that their green performance are relatively better than those who have not been affiliated with the federation. Therefore, the 
findings of this study may present a more optimistic picture of the sector, which could be further investigated in future with a bigger sample size from different regions in China. In addition, future studies could also explore the impact of early versus late implementation of green practices on the performance of SMEs over the packaging life cycle.

Global concerns over the environmental impacts of packaging have prompted governments to introduce stringent policies and regulations to encourage companies to adopt environmental friendly practices. In past the focus was mostly on consumer and retail packaging, however recently, increased discussions over the environmental impacts of industrial packaging are found. Future studies could further explore the sustainability issues in the supply chain of industrial packaging. It would be also interesting to explore how SMEs evolve and adopt changing environmental regulations in different countries. This study could also be replicated in other countries in Asia, like Malaysia, Thailand and Indonesia. These countries have similar cultural and market situations as China in developing green supply chain practices (Rao 2002, Zhu and Sarkis 2004).

\section{Disclosure statement}

No potential conflict of interest was reported by the authors. 


\section{References}

Accrosi, R., Cascini, A., Cholette, S., Manzini, R., Mora, C. 2014. Economic and environmental assessment of reusable plastic containers: a food catering supply chain case study. International Journal of Production Economics, 152, 88-101.

Bai, X.M., Hidefumi, I. 2001. Towards sustainable urban water resource management: a case study in Tianjin, China. Sustainable Development, 9, 23-35.

Bech-Larsen, T. 1996. Danish consumers' attitudes to the functional and environmental characteristics of food packaging. Journal of Consumer Policy, 19, 339-363.

Bras, B., McIntosh, M.W. 1999. Product, process, and organizational design for remanufacture - an overview of research. Robotics and Computer-Integrated Manufacturing, 15(3), $167-178$

Brown, D. 1993. Plastics packaging of food products: the environmental dimension. Trends in Food Science \& Technology, 4(9), 294-300.

Carter, C.R., Ellram, L.M. 1998. Reverse logistics: a review of the literature and framework for future investigation. Journal of Business Logistics, 19, 85-102.

Chaabane, A., Ramudhin, A., \& Paquet, M. (2011). Designing supply chains with sustainability considerations. Production Planning \& Control, 22(8), 727-741.

Cherrafi, A., Elfezazi, S., Garza-Reyes, J.A., Benhida, K., Mokhlis, A. (2017), Barriers in Green Lean implementation: a combined Systematic Literature Review and Interpretive Structural Modelling approach, Production Planning \& Control: The Management of Operations, Vol. 28, No. 10, pp. 829-842.

Chen, C. 2005. Incorporating green purchasing into the frame of ISO1400. Journal of Cleaner Production, 13(9), 927-933.

Chen, J. 2006. Development of Chinese small and medium-sized enterprises. Journal of Small Business and Enterprise Development, 13(2), 140-147.

Clark, G. 2000. Developing better systems for communications: environmental best practice in small business. In Hillary, R. (Ed.). Small and medium-sized enterprises and the environment. Sheffield, England: Greenleaf. 
Darnall, N. Jolley, G.J., Handfield, R. 2008. Environmental management systems and green supply chain management: complements for sustainability. Business Strategy and the Environment, 18, 30-45.

Davies, J., Hochman, S. 2007. The greening of the supply chain. Supply Chain Management Review, 11(5), 13-14.

Deegan, C., Gordon, B. 1996. A study of the environmental disclosure policies of Australian corporations. Accounting and Business Research, 26(3), 187-199.

Diabat, A., Govindan, K. 2011. An analysis of the drivers affecting the implementation of green supply chain management. Resources, Conservation and Recycling, 55(6), 659-667.

European Council. 1994. Directive 94/62/EC on packaging and packaging waste. Official Journal of European Union, 365, 10-23.

EPA. 1998. Inside flexo: a cleaner run for the money. Washington, D.C: EPA.

Flick, U. 2014. An introduction to qualitative research, (5th ed). London, England: Sage Publications.

Flynn, B.B., Sakakibara, S., Schroeder, R.G., Bates, K.A. and Flynn, E.J., 1990. Empirical research methods in operations management. Journal of operations management, 9(2), 250-284.

Garza-Reyes, J.A., Villarreal, B., Kumar, V., Molina Ruiz, P. (2016), Lean and Green in the Transport and Logistics Sector - A Case Study of Simultaneous Deployment, Production Planning \& Control: The Management of Operations, Vol. 27, No. 15, pp. 1221-1232.

Gilbert, S. 2001. Greening supply chain: enhancing competitiveness through green productivity. Taipei, Taiwan: Asian Productivity Organization.

Golafshani, N. 2003. Understanding reliability and validity in qualitative research. The qualitative report, 8(4), pp.597-606.

Gopal, P.R.C. and Thakkar, J., 2016. Sustainable supply chain practices: an empirical investigation on Indian automobile industry. Production Planning \& Control, 27(1), pp.49-64. 
Guide, V.D.R., Spencer, M.S., Srivastava, R. 1996. Are production systems ready for the green revolution? Production and Inventory Management Journal, 4, 70-78.

Gungor, A., Gupta, S.M. 1999. Issues in environmentally conscious manufacturing and product recovery: a survey. Computers \& Industrial Engineering, 36, 811-853.

Hall, J. 2000. Environmental supply chain dynamics. Journal of Cleaner Production, 8(6), 455471.

Handfield, R., Melnyk, S., Calantone, R., Curcovic, S. 2001. Integrating environmental concerns into the design process: the difference between theory and practice. IEEE Transactions in Engineering Management, 48, 189-208.

Hsu, C.C., Tan, K.C., Zailani, S.H.M., Jayaraman, V. 2013. Supply chain drivers that foster the development of green initiatives in an emerging economy. International Journal of Operations \& Production Management, 33(6), 656-688.

Hu, A. H., and C. W. Hsu. 2010. "Critical factors for implementing green supply chain management practice: an empirical study of electrical and electronics industries in Taiwan". Management research review, 33(6), 586-608.

Huang, J. 2017. Sustainable Development of Green Paper Packaging, Environment and Pollution, 6 (2), page $1-7$.

King, N. 2004. Using interviews in qualitative research. In Cassell, C., Symon, G. (Ed.). Essential guide to qualitative methods in organizational research. (6th ed.) (pp. 11-22). London: Sage.

Jabbour, C.J., Mauricio, A.L. and Jabbour, A.B.L.D.S., 2017. Critical success factors and green supply chain management proactivity: shedding light on the human aspects of this relationship based on cases from the Brazilian industry. Production Planning \& Control, 28(6-8), pp.671-683.

Kumar, V., Holt, D., Ghobadian, A., \& Garza-Reyes, J. A. (2015). Developing green supply chain management taxonomy-based decision support system. International Journal of Production Research, 53(21), 6372-6389.

Kvale, S., Brinkmann, S. 2009. Interviews (2nd ed). Thousand Oaks, CA: Sage. 
Production Planning \& Control: The Management of Operations 2019;30(5-6):464-478.

Lai, K. H., Wong, C. W. Y. 2012. Green logistics management and performance: Some empirical evidence from Chinese manufacturing exporters, Omega, 40 (3), 267-282.

Lee, S-Y. 2008. Drivers for the participation of small and medium-sized suppliers in green supply chain initiatives. Supply Chain Management: An International Journal, 13(3), 185-198.

Lee, V.H., Ooi, K.B., Chong, A.Y.L. and Lin, B., 2015. A structural analysis of greening the supplier, environmental performance and competitive advantage. Production Planning \& Control, 26(2), pp.116-130.

Lewis, H. 2005. Defining product stewardship and sustainability in the Australian packaging industry. Environmental Science \& Policy, 8, 45-55.

Lin Y., Ho, H. 2008. An empirical study on logistics services provider, intention to adopt green innovations. Journal of Technology, Management and Innovation, 3(1), 17-26.

López-Torres, G. C., Garza-Reyes, J. A., Maldonado-Guzmán, G., Kumar, V. Rocha-Lona, L. and Cherrafi, A. (2017), Knowledge management for sustainability in operations, Production Planning \& Control (In Press)

Luken, R., Stares, R. 2005. Small business responsibility in developing countries: a threat or an opportunity? Business Strategy and the Environment, 14, 38-53.

Luthra, S., Garg, D. and Haleem, A., 2015. Critical success factors of green supply chain management for achieving sustainability in Indian automobile industry. Production Planning \& Control, 26(5), pp.339-362.

Luthra, S., Kumar, V., Kumar, S., Haleem, A. 2011. Barriers to implement green supply chain management I automobile industry using interpretive structural modelling technique-an Indian perspective. Journal of Industrial Engineering and Management, 4(2), 231-257.

Marshall, D., McCarthy, L., Heavey, C., \& McGrath, P. (2015). Environmental and social supply chain management sustainability practices: construct development and measurement. Production Planning \& Control, 26(8), 673-690.

McMillan, J. and Schumacher, S., 2006. Research in education. $6^{\text {th }}$ ed., Boston: Pearson Education. 
Production Planning \& Control: The Management of Operations 2019;30(5-6):464-478.

Meikle, J. 1995. American plastic: a cultural history. New Brunswick: Rutgers University Press.

Min, H., Galle, W.P. 2001. Green purchasing practices of US firms. International Journal of Operations \& Production Management, 21, 1222-1238.

Mohanty, R.P. and Prakash, A., 2014. Green supply chain management practices in India: an empirical study. Production Planning \& Control, 25(16), pp.1322-1337.

Patton, M.Q. 2002. Qualitative research and evaluation methods. Thousand Oaks, CA: Sage Publications.

Pohlen, T.L., Farris, M.T. 1992. Reverse logistics in plastics recycling. International Journal of Physical Distribution \& Logistics Management, 22(7), 35-47.

Rao, P. 2002. Greening the supply chain: a new initiative in South East Asia. International Journal of Operations and Production Management, 21(6), 632-635.

Rao, P. 2007. Greening of the supply chain: an empirical study for SMEs in the Philippine context. Journal of Asia Business Studies, 1(2), 55 - 66.

Rao, P., Holt, D. 2005. Do green supply chains lead to competitiveness and economic performance? International Journal of Operation \& Production Management, 25(9), 898-916.

Roper, S., Parker, C. 2006. How (and where) the mighty have fallen: branded litter. Journal of Marketing Management, 22, 473-487.

Roy, R., Whelan, R.C. 1992. Successful recycling through value-chain collaboration. Long Range Planning, 25, 62-71.

Russo, D., Rizzi, C. 2014. Structural optimization strategies to design green products. Computers in Industry, 65, 470-479.

Sarkis, J. 2003. A strategic decision framework for green supply chain management. Journal of Cleaner Production, 11, 397-409.

Srivastava, K.S. 2007. Green supply-chain management: a state-of-the-art literature review. International Journal of Management Reviews, 9(1), 27-30. 
Svanes, E., Vold, M., Moller, H., Pettersen.M.K., Larsen, H., Hanssen, O.J. 2010. Sustainable packaging design: a holistic methodology for packaging design. Packaging Technology and Science, 23, 161-175.

Tabone, M.D., Cregg, J.J., Beckman, E.J., Landis, A.E. 2010. Sustainability metrics: life cycle assessment and green design in Polymers. Environmental Science \& Technology, 44(21), 8264-8269.

Tseng, M.L., Tan, K.H., Lim, M., Lin, R.J. and Geng, Y., 2014. Benchmarking eco-efficiency in green supply chain practices in uncertainty. Production Planning \& Control, 25(1314), pp.1079-1090.

Vachon, S., Klassen, R.D. 2008. Environmental management and manufacturing performance: the role of collaboration in the supply chain. International Journal of Production Economics, 111(2), 299-315.

Van Hoek, R.I., Erasmus. 2000. From reversed logistics to green supply chains. Logistics Solutions Issue, 2, 28-33.

Verghese, K., Lewis, H. 2007. Environmental innovation in industrial packaging: a supply chain approach. International Journal of Production Research, 45(18-19), 4381-4401.

Walker, H., Di Sisto, L., McBain, D. 2008. Drivers and barriers to environmental supply chain management practices: lessons from the public and private sectors. Journal of Purchasing and Supply Management, 14(1), 69-85.

Wikstrom, F., Williams, H., Verghese, K., Clune, S. 2014. The influence of packaging attributes on consumer behaviour in food-packaging life cycle assessment studies- a neglected topic. Journal of Cleaner Production, 73, 100-108.

Williams, H., Wikstrom, F. 2010. Environmental impact of packaging and food losses in a life cycle perspective: a comparative analysis of five food items. Journal of Cleaner Production, 19(1), 43-48.

Xueyan, Y.A.O., 2015. Research on Green Strategies for Packaging Design. China Packaging Industry, 16, p.030. 
Ytterhus, B.E., Arnestad, P., Lothe, S. 1999. Environmental initiatives in the retailing sector: an analysis of supply chain pressures and partnerships. Eco-Management and Auditing, 6(4), 181-188.

Yin, R.K., 2011. Applications of case study research. Sage Publications Ltd. London, UK.

Yin, R.K., 2017. Case study research and applications: Design and methods. Sage publications Ltd. London, UK.

Yu, W., Chavez, R. and Feng, M., 2017. Green supply management and performance: a resource-based view. Production Planning \& Control, 28(6-8), pp.659-670.

Zailani, S., Jeyaraman, K., Vengadasan, G., Premkumar, R. 2012. Sustainable supply chain management (SSCM) in Malaysia: a survey. International Journal of Production Economics, 140, 330-340.

Zhang, H.C., Kuo, T.C., Lu, H., Huang, S.H. 1997. Environmentally conscious design and manufacturing: a state-of-the-art survey. Journal of Manufacturing Systems, 16(5), 352371.

Zhang, V.I., Ursacki, T., Nemetz, P. 1999. Can China be a clean tiger? Growth Strategies and Environmental Realities, 72(1), 23-37.

Zhang, G., Zhao, Z. 2012. Green packaging management of logistics enterprises. Physics Procedia, 24, 900-905.

Zhu, Q., Geng, Y. 2001. Integrating environmental issues into supplier selection and management. Greener Management International, 35, 27-40.

Zhu, Q., Sarkis, J. 2004. Relationships between operational practices and performance among early adopters of green supply chain management practices in Chinese manufacturing enterprises. Journal of Operations Management, 22, 265-289.

Zhu, Q. and Sarkis, J., 2006. An inter-sectoral comparison of green supply chain management in China: drivers and practices. Journal of cleaner production, 14(5), 472-486.

Zhu, Q., Sarkis, J., Geng, Y. 2005. Green supply chain management in China: pressures, practices and performance. Green Supply Chain Management, 25(5), 449-468. 
Production Planning \& Control: The Management of Operations 2019;30(5-6):464-478.

Zhu, Q., Zhang, L. 2004. Green purchasing in coal-burning power plants. Energy Conservation \& Environmental Protection, 13(2), 18-20.

Zhu, Q., Sarkis, J., Cordeiro, J. J., Lai ,K. H.. 2008. Firm-level correlates of emergent green supply chain management practices in the Chinese context. Omega, 36(4), 577-591.

Zhu, Q., Tian, Y. and Sarkis, J., 2012. Diffusion of selected green supply chain management practices: An assessment of Chinese enterprises. Production Planning \& Control, 23(1011), pp.837-850.

Zsidisin, G.A., Siferd, S.P. 2001. Environmental purchasing: a framework for theory development. European Journal of Purchasing and Supply Management, 7(1), 61-73. 